\title{
Vapor-dynamic cooling systems for nuclear power plants
}

\author{
Sergey Shcheklein* \\ Ural Federal University, Department of Nuclear Power Plants and Renewable Energy Sources, \\ 620002, Yekaterinburg, st. Mira 19, Russia
}

\begin{abstract}
Are the results of the pilot study intensive cooling pools extracts of spent nuclear fuel at nuclear power plants using vapor-dynamic technology. The possibility of passive heat dissipation energy axially heat flow density above $10^{6} \mathrm{~W} / \mathrm{m}^{2}$.
\end{abstract}

\section{Introduction}

One of the most dangerous situations leading to bdba NPP is long due. In such emergency conditions the main task of the security systems is the preservation of the integrity of the reactor and the spent nuclear fuel (SNF), located in prereactor spent fuel pool (SFP).

The need to comply with this requirement became apparent after accident and the Japanese Fukushima-1. The creators of nuclear power plant got a new challenge of removing heat from the SFP passive systems.

The loss of heat removal led to heating and evaporation of the coolant in the active zones and cooling water in the SFP, that caused the overheating nuclear fuel from its damage and the formation of large quantities of hydrogen. hydrogen Accumulation under the protective shell of the reactor, and then and in the building of the reactor compartment, leading to explosions with a significant destruction of buildings.

Existing systems that ensure the removal of residual heat from SFP, systems are "active" principle of applying cooling water by circulation pumps. Therefore, in the conditions of a long-term loss of power supply for own needs and the impossibility of connecting emergency sources of electrical energy, the provision of a normal discharge of residual heat of spent nuclear fuel is determined by the time of evaporation of water from SFP and amounts to several days to several hours, depending on the SFP loading. An increase in temperature with subsequent evaporation of water will lead to the beginning of the steam-zirconium reaction with the formation of hydrogen. When the outer surface of the shells of fuel elements of SNF is bare, the conditions for normal heat removal are violated, which leads to their damage and becomes the cause of a radiation accident.

At the same time, the need to create passive systems, usually based on the principles of natural convection, conflicted with the need to reduce the volume of buildings and structures of NPP, because by virtue of the low intensity of heat transfer processes requires

\footnotetext{
* Corresponding author: s.e.shcheklein@urfu.ru
} 
considerable heat exchange surfaces, low hydraulic resistance tracts and significant walkthrough sections cooling medium.

Interest of creators of new technologies cause more intense than natural convection heat transfer methods environment medium, based on natural principles under relatively small thermal conditions. One such method is the use of the difference of the densities of liquids and vapors in the gravitational field, implemented in designs of two-phase thermosyphons [1]. A detailed theoretical analysis of the use of this heat removal technology was carried out in [2], where the principle possibility and effectiveness of the use of the thermosyphon method. However, despite the apparent simplicity and good knowledge of the thermophysical processes taking place in these devices, the available theoretical and experimental data are insufficient to reliably determine the transmitted power, to select and create a design of heat exchange equipment capable of reliably thermally stabilizing the soak pool SNF [3-6].

The purpose of this work is the experimental substantiation of the possibility of using one of the thermosyphon method variants-the steam dynamic deviation of heat from the protected object (SFP SNF).

\section{The methodology of experimental research}

The experiments were carried out on two organic low-boiling heat transfer fluids-ethanol and acetone with different temperatures start steaming. The heat exchanger-evaporator of the circuit was heated by two methods:

- hot air-using the heat gun;

- water heated up to $90^{\circ}$ with by placing it in the tank thermostat.

The installation path was a long stretch of pipelines, the efferent formed in evaporator couples located above the heat exchanger-air cooled condenser; the resulting condensate is returned by gravity into the evaporator. Cooling heat exchanger-condenser proceeded convection air.

Installation path had significant dimensions, so the total length of the steam and condensate pipelines exceeding 15 meters, which is required for heat dissipation over considerable distances in projects of modern nuclear power plant. Processes of evaporation, condensation, steam and condensate flows develop in time and have a nonstationary nature. View the basic units of the pilot stand is shown in Figure 1.

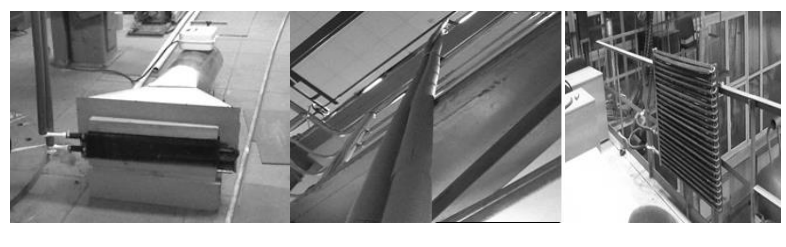

a

$\mathrm{b}$

$\mathrm{c}$

Fig. 1. The main components of the experimental stand a-evaporation section; b-transport pipeline; c- condensation section

For information about changes of temperatures and pressures in the long path was developed by fast automated measuring complex consisting of analog-to-digital converter is compatible with the personal computer and multiplexer temperature sensors. The system allows in automatic mode to produce synchronous multi-channel measurement temperature with simultaneous formation of the array data in the computer's memory. The symbols of the temperature sensors and their location on the plant circuit are given in Table. 2. 
Table 2. The designation and location of thermocouples

\begin{tabular}{|c|c|}
\hline Designation & Location \\
\hline 1 & The output of the evaporator \\
\hline 2 & Upstream, at a height of $2 \mathrm{~m}$ from the evaporator \\
\hline 3 & Upstream, at an altitude of $5 \mathrm{~m}$ from the evaporator \\
\hline 4 & Entrance into the condenser \\
\hline 5 & Output capacitor \\
\hline 6 & The downward flow, at an altitude of $5 \mathrm{~m}$ from the evaporator \\
\hline 7 & The downward flow, at an altitude of $5 \mathrm{~m}$ from the evaporator \\
\hline 8 & Evaporator inlet \\
\hline
\end{tabular}

\section{The results of research}

Results of experimental researches for acetone are shown in Fig. 2 . Studies were carried out in non-stationary mode, when heating of the evaporator water heated to $90^{\circ} \mathrm{C}$ water, by putting it into the tank thermostat.

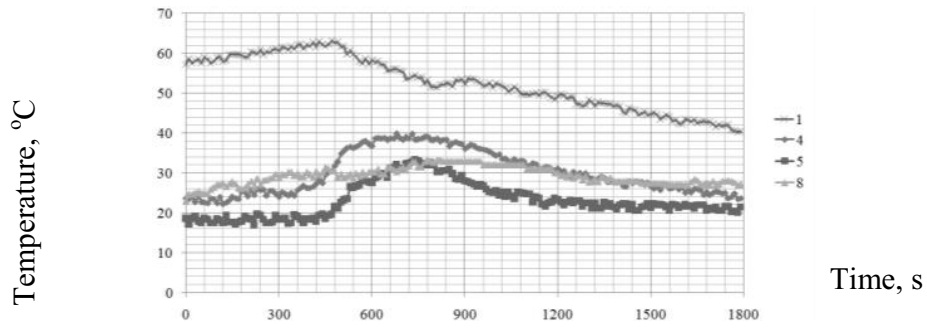

Fig. 2. Temperature dependence of characteristic points from time to time for acetone

The second series of experiments was carried out using as coolant ethanol. The studies were conducted in the stationary mode when heated by hot air, filed by using the eat gun. The results of these studies are shown in the figure. 3 .

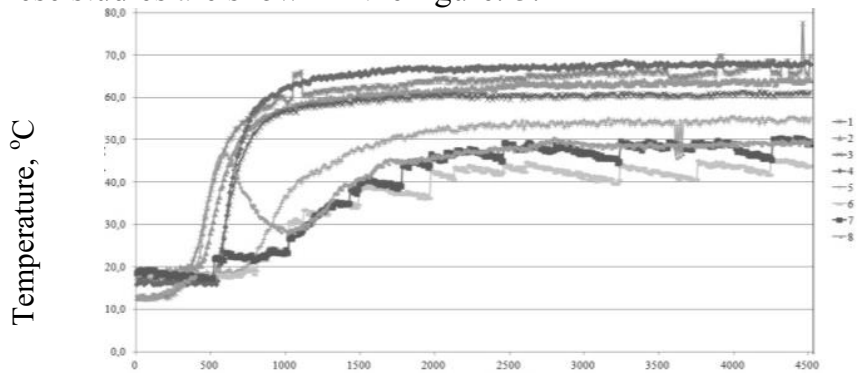

Time, s

Fig. 3 Temperature dependence of characteristic points from time to time for ethanol.

\section{Discussion on and analysis of the results of the study}

Data experiments as for acetone and ethyl alcohol obtained both stationary and nonstationary methods show the following:

-when all studied thermal loads in parodinamicheskom circuit appeared steady circulation phases, there were no limitations of heat pipes and thermosyphons, including associated with condensate steam rising movement obstacle thread; 
-after a transition process associated with warming and vaporization of stabilization occurs beginning temperature and pressure in the circuit.

Score transmitted heat output path in unsteady mode according to the number of allotted heat from the tank with heated at $90{ }^{\circ} \mathrm{C}$ with water and heat exchanger-condenser announcement:

-full power assigned to heat exchanger-evaporator by heating medium:

$$
Q=V \cdot \rho \cdot c_{p} \cdot \Delta t / \tau, W
$$

-heat flux density in heat exchanger-evporator:

$$
q=Q / L \cdot S, W / m^{2},
$$

- heat flux density in axial direction:

$$
q_{o c}=4 \cdot Q / \pi \cdot D^{2}, W / m^{2}
$$

where: $V$-the volume of hot water in the tank, $\mathrm{m}^{3}, \rho, \mathrm{C}_{p}$-density and specific heat capacity of water, $\mathrm{kg} / \mathrm{m}^{3}$ and $\mathrm{j} / \mathrm{kg}, \Delta t$-water temperature change in process of heat dissipation, $\tau$ measurement time, sec., $L, S$-length and perimeter pipe in heat exchanger evaporator, m, $D$ - diameter of pipelines of heat transfer circuit, $m$.

The processing of the measurement results with the aid of relations (1-3) made it possible to evaluate the heat transfer capacity of the vapor-dynamic circuit. Results of processing are given in table 3 .

Table 3. Thermal transfer power of the vapor-dynamic circuit

\begin{tabular}{|c|c|c|c|}
\hline $\begin{array}{c}\text { The } \\
\text { centrality } \\
\text { of power, } \mathrm{w}\end{array}$ & $\begin{array}{c}\text { The centrality of } \\
\text { power without the } \\
\text { heat loss, } \mathrm{W}\end{array}$ & $\begin{array}{c}\text { The density of heat flow } \\
\text { in the evaporator, } \mathrm{kW} / \mathrm{m}^{2}\end{array}$ & $\begin{array}{c}\text { Heat density } \\
\text { in the axial flow } \\
\text { the direction of a path, } \mathrm{kW} / \mathrm{m}^{2}\end{array}$ \\
\hline 465 & 445 & 3.44 & $2.21 \cdot 10^{3}$ \\
\hline
\end{tabular}

\section{Conclusions}

It has been experimentally shown that it is possible to divert considerable thermal power over considerable distances (over $10 \mathrm{~m}$ ) using a developed vapor-dynamic circuit with lowboiling heat carriers. The results of axial transfers of heat are very high (above $10^{6} \mathrm{~W} / \mathrm{m}^{2}$ ) and can be further increased by intensification of heat exchange (finning) both from the evaporator side (cooled zone) and from the condenser side (heat removal zone).

The work was carried out with the financial support of the Government of the Russian Federation, Decree No. 211, Contract No. 02.A03.21.0006

\section{References}

1. I.L. Pioro, L.O. Antonenko, L.C. Pioro, Effective heat exchangers with two-phase thermosyphon (Kiev, 1991) [in Russian]

2. M.K. Bezrodniy, I.L. Pioro, T. Kostiuk, Transport processes in two-phase thermosiphon systems. Theory and practice. (Kiev, 2005) [in Russian]

3. L.L. Vasilyev, V.G. Kiselev, Yu.N. Matveev, F.F. Molodkin, Heat exchanger, heat pipes (Minsk, Nauka i tekhnika, 1987) [in Russian]

4. D. Japikse, R.F. Winter, Int. J. Heat Mass Transfer 14, 427 (1971).

5. A.V. Podoprigora, I.I. Sviridenko, D.V. Shevelev, Vestnik Sevntu 119 (2011)

6. S.E. Shcheklein, E.V. Starikov, Yu.E. Nemikhin, A.D. Nikitin, A.V. Zhukov, S.A. Korzhavin, Int. Sci. J. Alternative Energy Ecology 86, (2015) 